\title{
THE ROLE OF SOCIOECONOMIC STATUS, LIFESTYLE FACTORS AND ADIPOSITY IN THE ASSOCIATION BETWEEN C-REACTIVE PROTEIN AND METABOLIC RISK
}

Cindy George ${ }^{1}$, Juliet Evans², Lisa K. Micklesfield ${ }^{3,4}$, Naomi S. Levitt', Estelle V. Lambert ${ }^{4}$, Tommy Olsson ${ }^{6}$, Julia H. Goedecke ${ }^{1,4}$

'Non-communicable Disease Research Unit, South African Medical Research Council, Cape Town, South Africa; ${ }^{2}$ Health Impact Assessment, Western Cape Department of Health, Cape Town, South Africa; ${ }^{3}$ South African Medical Research Council/University of the Witwatersrand, Developmental Pathways for Health Research Unit, Department of Pediatrics, Faculty of Health Sciences, University of Witwatersrand, Johannesburg, South Africa; ${ }^{4}$ Division of Exercise Science and Sports Medicine, Department of Human Biology, University of Cape Town, Cape Town, South Africa; ${ }^{5}$ Diabetes and Endocrine Unit, Department of Medicine, University of Cape Town, Cape Town, South Africa;

\section{INTRODUCTION}

AIMS

\section{METHODS}

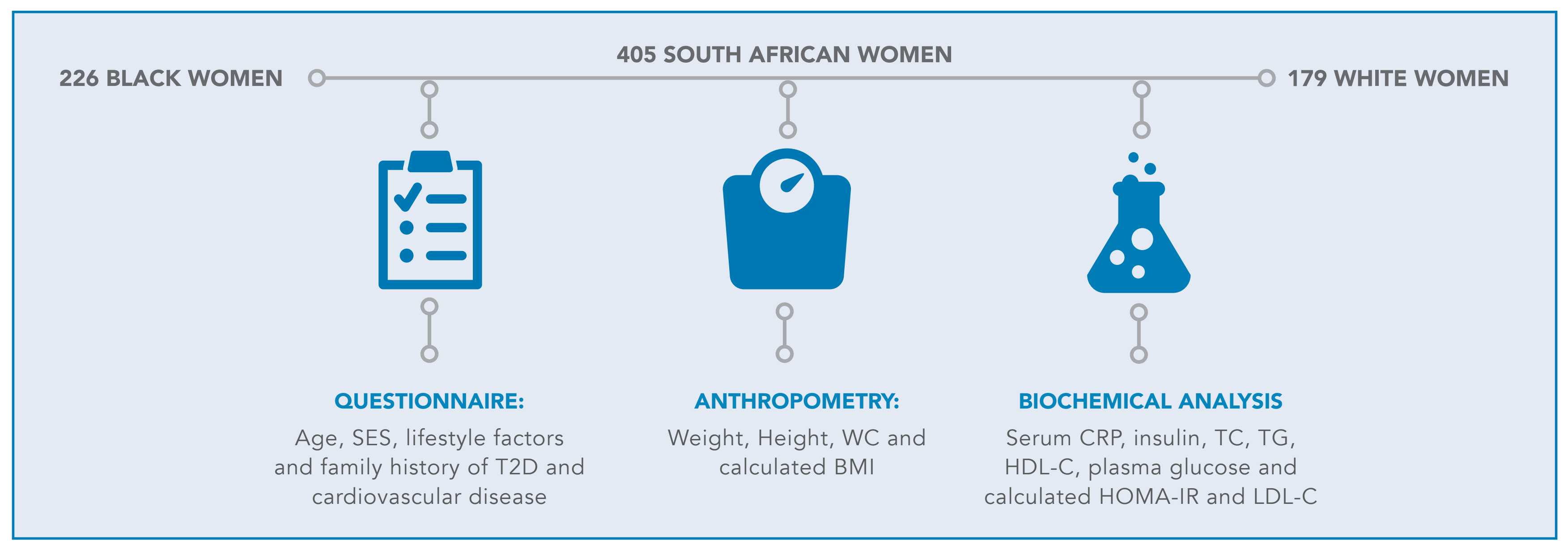

Figure 1: Schematic diagram of study methods

\section{RESULTS}

Table 1: Age, anthropometry, and blood based markers in black and white SA women

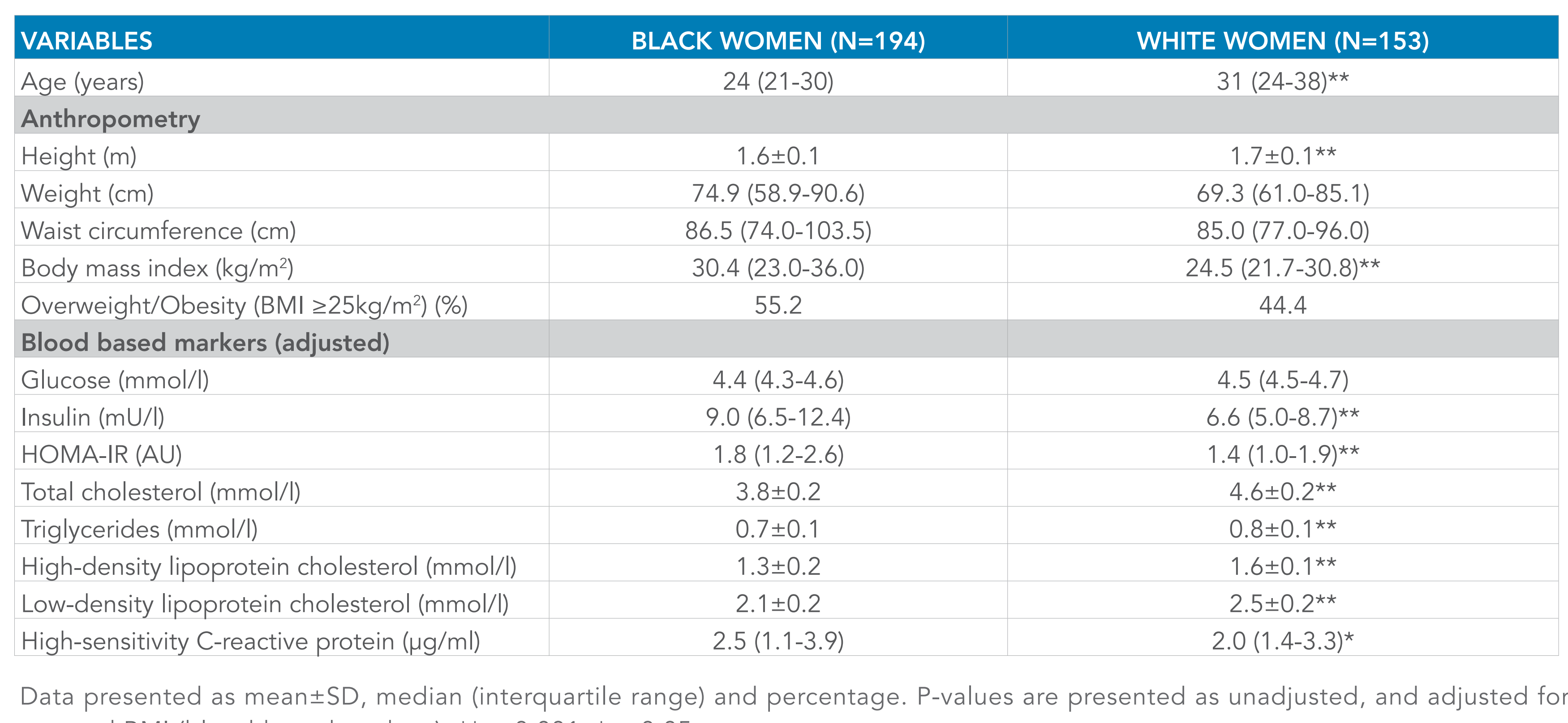

Table 2: SES and lifestyle factors of black and white SA women

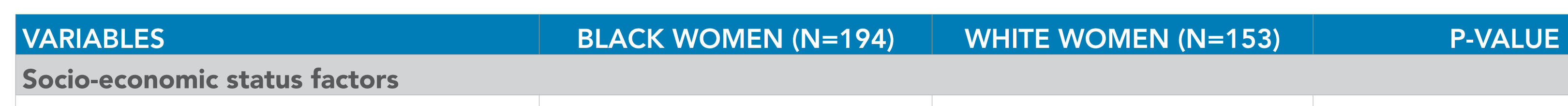

Socio-economic status factors

Education (\%)

Have not completed high
Completed high schoo

Housing density (persons/room)

WHITE WOMEN $(\mathrm{N}=153)$

P-VALUE

ex (amenitieshouse)

Lifestyle factors

Smoking status (\%)

Current smoker

Daily alcohol use (\%)

Non-drinker

Physical activity (\%)

Insufficiently active $(<150 \mathrm{~min} /$ week $)$

Sufficiently active $(\geq 150$

None

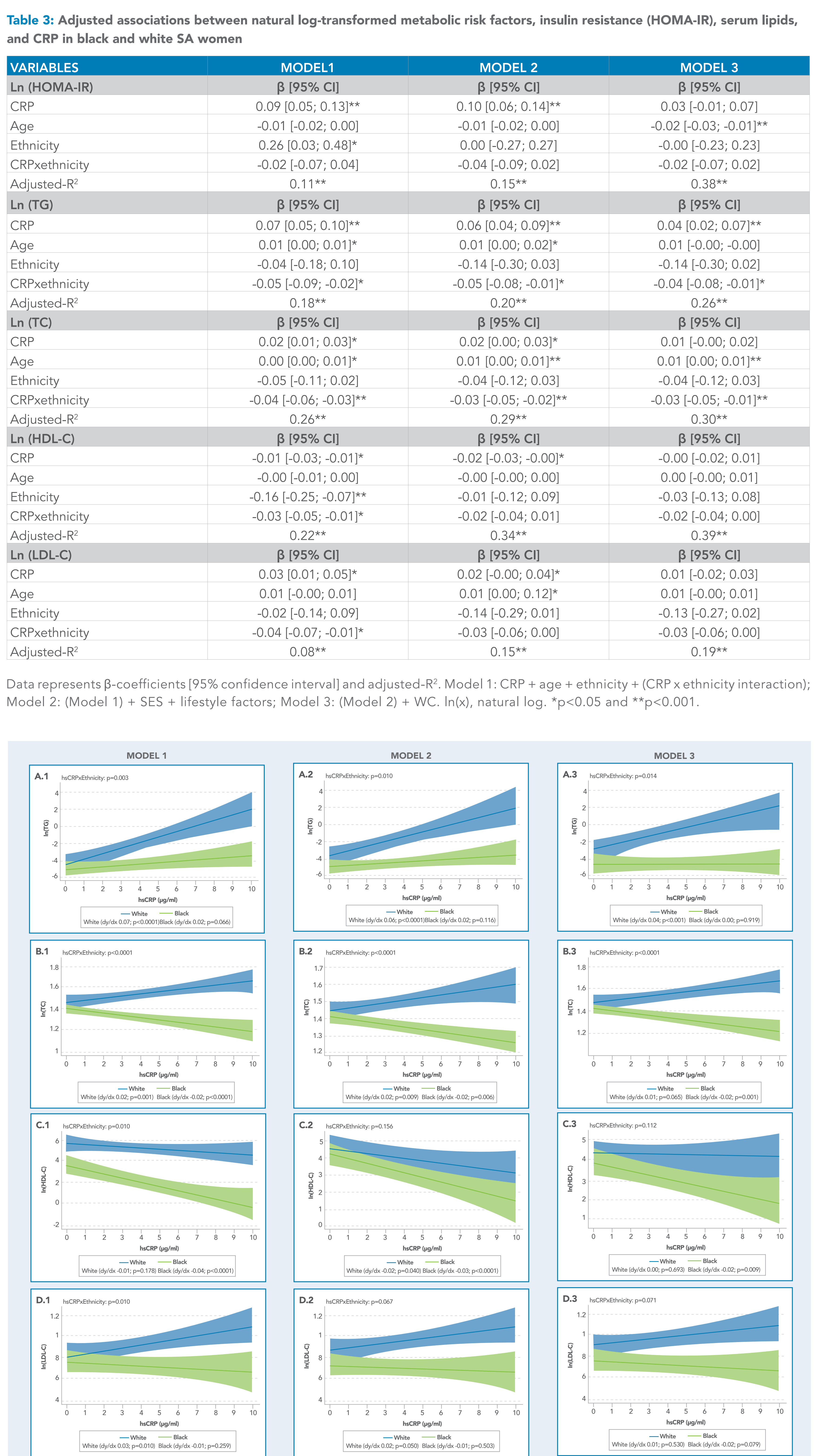

Figure 2: Adjusted as

Data is presented as

CRP and lipid marke

\section{CONCLUSION}

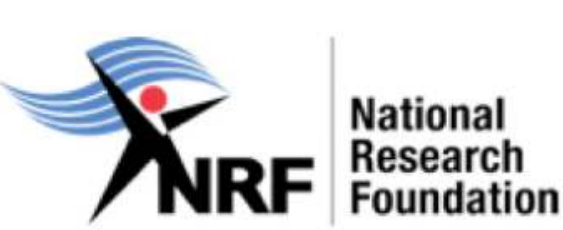

